\title{
Conformational and structural analysis of 2-allyl-1,2-benzisothiazol-3(2H)-one 1,1-dioxide as probed by matrix-isolation spectroscopy and quantum chemical calculations
}

\author{
Andrea Gómez-Zavaglia ${ }^{\mathrm{a}, \mathrm{b}, *}$, Agnieszka Kaczor ${ }^{\mathrm{a}, \mathrm{c}}$, Daniela Coelho ${ }^{\mathrm{a}, \mathrm{d}}$, M. Lurdes S. Cristiano ${ }^{\mathrm{d}}$, Rui Fausto ${ }^{\mathrm{a}, *}$ \\ a Department of Chemistry, University of Coimbra, Rua Larga, Coimbra P-3004-535, Portugal \\ ${ }^{\mathrm{b}}$ Faculty of Pharmacy and Biochemistry, University of Buenos Aires, C.P. 1113 Buenos Aires, Argentina \\ ${ }^{c}$ Faculty of Chemistry, Jagiellonian University, Ingardena 3, 30-060 Krakow, Poland \\ ${ }^{\mathrm{d}}$ Department of Chemistry and Biochemistry, F.C.T., and CCMAR, University of Algarve, Campus de Gambelas, 8005-039 Faro, Portugal
}

\section{A R T I C L E I N F O}

Article history:

Received 23 July 2008

Accepted 15 September 2008

Available online 23 September 2008

\section{Keywords:}

Benzisothiazoles

Molecular structure

IR spectra

Matrix isolation

Molecular orbital calculations

\begin{abstract}
A B S T R A C T
2-Allyl-1,2-benzisothiazol-3(2H)-one 1,1-dioxide (ABIOD) has been studied by matrix-isolation infrared spectroscopy and quantum chemical calculations. A conformational search on the B3LYP/6$311++G(3 \mathrm{df}, 3 \mathrm{pd})$ potential energy surface of the molecule demonstrated the existence of three conformers, $S k, S k^{\prime}$ and $C$, with similar energies, differing in the orientation of the allyl group. The calculations predicted the $S k$ form as the most stable in the gaseous phase, whereas the $S k^{\prime}$ and $C$ conformers have calculated relative energies of $c a$. 0.6 and $0.8-3.0 \mathrm{~kJ} \mathrm{~mol}^{-1}$, respectively (depending on the level of theory). In agreement with the relatively large $\left(>6 \mathrm{~kJ} \mathrm{~mol}^{-1}\right)$ calculated barriers for conformational interconversion, the three conformers could be efficiently trapped in an argon matrix at $10 \mathrm{~K}$, the experimental infrared spectrum of the as-deposited matrix fitting well the simulated spectrum built from the calculated spectra for individual conformers scaled by their predicted populations at the temperature of the vapour of the compound prior to matrix deposition. Upon annealing the matrix at $24 \mathrm{~K}$, however, both $S k$ and $S k^{\prime}$ conformers were found to convert to the more polar $C$ conformer, indicating that this latter form becomes the most stable ABIOD conformer in the argon matrix.
\end{abstract}

(c) 2008 Elsevier B.V. All rights reserved.

\section{Introduction}

Benzisothiazoles, also known as pseudosaccharins, are often vital structural units of biologically active systems. Their uses as herbicides, antibiotic agents and phospholipase inhibitors in the treatment of hepatic diseases have already been described [1-4]. Among benzisothiazoles, benzisothiazolones (2-alkyl-1,2-benzisothiazol-3(2H)-one 1,1-dioxides) and their derivatives have shown different functions, all of them related with their capacity to bind proteins. In this regard, they have been shown to bind the outer membrane of Pseudomonas aeruginosa and increase its resistance to antibiotics [5]. Other benzisothiazolones inhibit human leukocyte elastase (a serine protease) [6,7]. The synthesis of benzisothiazolone 1,1-dioxide-based serine protease inhibitors has been demonstrated to be efficient when carried out in solidphase [8]. In addition, it has also been shown that some benzisothiazolone derivatives selectively block binding of the estrogen receptor in breast cancer. Therefore, these compounds are being

\footnotetext{
* Corresponding authors. Tel.: +351 239 852080; fax: +351 239827703 (R Fausto).

E-mail addresses: angoza@qui.uc.pt (A. Gómez-Zavaglia), rfausto@ci.uc.pt (R. Fausto).
}

currently used in antiestrogen therapy for breast cancer [9]. More recently, a new class of substituted 2-benzisothiazolones has been proven to exhibit antiviral activity against retroviruses (e.g., HIV virus) [10].

Benzisothiazolyl ethers derived from phenols, benzyl and naphthyl alcohols are easily obtained from reaction of the corresponding hydroxylic compound with 3-(chloro)-1,2-benzisothiazole 1,2-dioxide. The benzisothiazolyl system, together with oxygen from the original alcohol, represents an efficient nucleofuge in heterogeneous transfer hydrogenolysis catalyzed by transition metals [11-13] or, in the case of aryloxybenzisothiazoles, cross-coupling with organometalic reagents [14]. Much of the reactivity of these ethers can be ascribed to changes in bond lengths about the central $\mathrm{C}_{\mathrm{AR}}-\mathrm{O}-\mathrm{C}_{\mathrm{A}}$ ether bonds $(\mathrm{AR}=$ heteroaromatic ring and $\mathrm{A}=$ alkyl or aryl group), caused by the powerful electron-withdrawing effect of the pseudosaccharyl ring systems. Therefore, the originally strong $\mathrm{C}_{\mathrm{A}} \mathrm{O}$ bond in the hydroxylic compound becomes weak, and the bond between the oxygen and the carbon of the heteroaromatic ring $\left(\mathrm{C}_{\mathrm{AR}}-\mathrm{O}\right)$ becomes very strong [15]. In allyl- and alkylpseudosaccharyl ethers, the net result of the electronic changes is also important, in that it provides a molecular structure that lies close to a transition state structure, in which the originally strong $\mathrm{C}_{\mathrm{A}}-\mathrm{O}$ bond in the ether becomes easily cleavable to give the ther- 
mally isomerised $\mathrm{N}$-allyl or $\mathrm{N}$-alkyl isomers, 2-allyl- or 2-alkyl-1,2benzisothiazol-3(2H)-one 1,1-dioxides (benzisothiazolones), respectively, through Claisen- or Chapman-like rearrangements [16-19].

In spite of their important role in chemical and biological sciences and medicine, to the best of our knowledge neither structural nor vibrational studies have been carried out on these compounds hitherto. For this reason, in the present study 2-allyl-
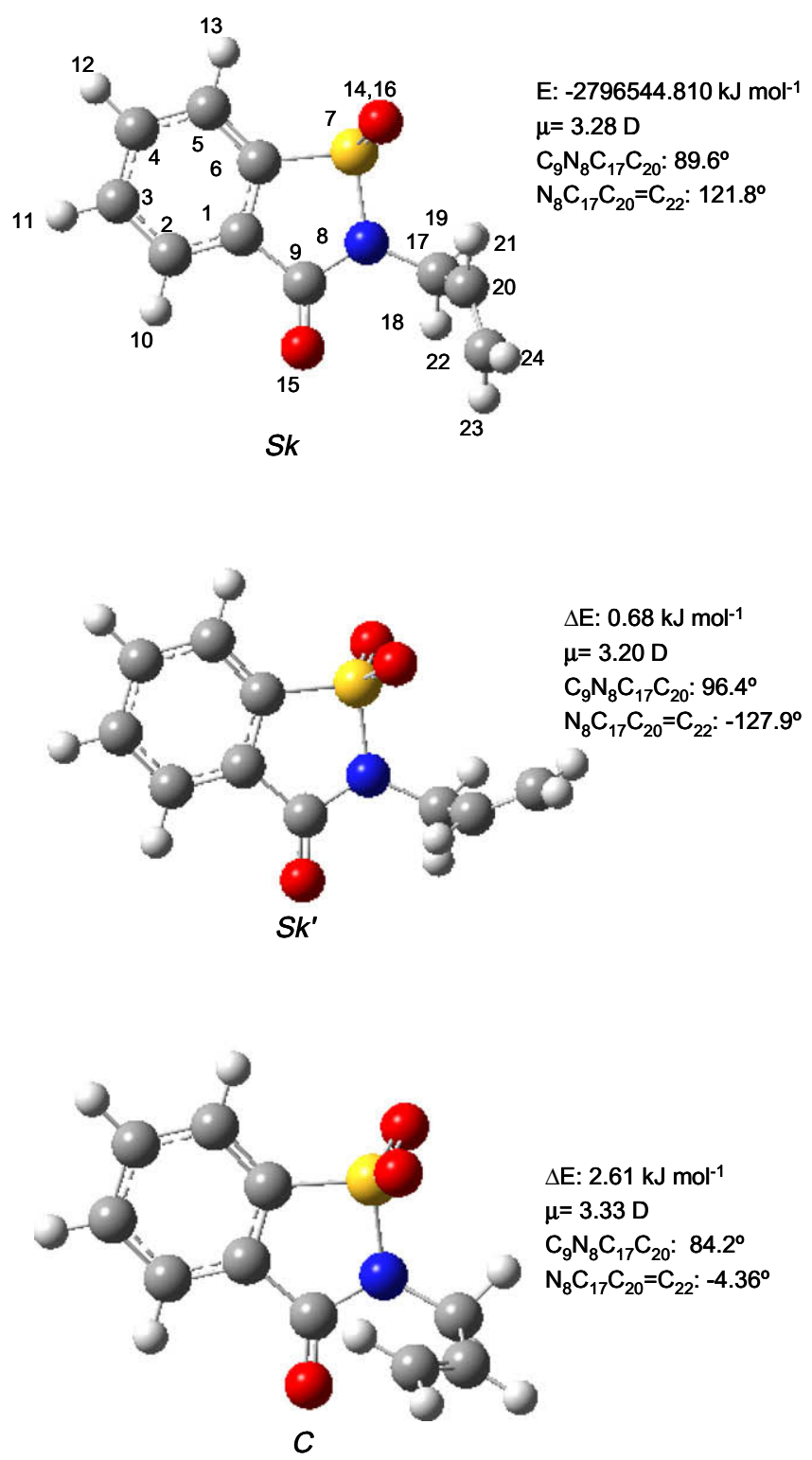

Fig. 1. Conformers of 2-allyl-1,2-benzisothiazol-3(2H)-one 1,1-dioxide (ABIOD) with chosen atom numbering scheme.
1,2-benzisothiazol-3(2H)-one 1,1-dioxide (ABIOD) was structurally investigated, with the aim of achieving a deeper understanding of both its electronic structure and conformational preferences. Matrix-isolation infrared spectroscopy and quantum chemical calculations have been selected as methods of study. The molecules of ABIOD have then been isolated in their monomeric form in argon matrices, characterized structurally, and their vibrational signatures determined. Annealing of the matrices led to promotion of conformational isomerisation reactions, which enabled us to get insight on the intramolecular dynamics of the compound. The interpretation of the experimental results is supported by extensive MP2 and DFT calculations, using basis sets that include highorder polarization functions.

\section{Materials and methods}

\subsection{Infrared spectroscopy}

2-Allyl-1,2-benzisothiazol-3(2H)-one 1,1-dioxide (ABIOD) [melting point: $87-89^{\circ} \mathrm{C}$ ] was obtained from the corresponding $O$-allyl isomer, 3-propenyloxy-1,2-benzisothiazole 1,1-dioxide, by heating a neat sample. 3-Propenyloxy-1,2-benzisothiazole 1,1dioxide was obtained through reaction of the allylic alcohol prop-2-en-1-ol, with 3-chloro-1,2-benzisothiazole 1,1-dioxide, using a synthetic methodology described elsewhere [16].

In the matrix-isolation experiments, a glass vacuum system and standard manometric procedures were used to deposit the matrix gas (argon, N60, obtained from Air Liquide). Matrices were prepared by co-deposition, onto the cooled CsI substrate of the cryostat, of the matrix gas (argon), and the compound placed in a specially designed temperature variable mini-oven assembled inside the cryostat. The temperature of the mini-oven used to evaporate ABIOD was $56{ }^{\circ} \mathrm{C}$. The IR spectra were collected, with $0.5 \mathrm{~cm}^{-1}$ spectral resolution, on a Mattson (Infinity 60AR Series) Fourier Transform infrared spectrometer, equipped with a deuterated triglycine sulphate (DTGS) detector and a $\mathrm{Ge} / \mathrm{KBr}$ beamsplitter.

All experiments were done on the basis of an APD Cryogenics close-cycle helium refrigeration system with a DE-202A expander. The temperature of deposition was $10 \mathrm{~K}$. Necessary modifications of the sample compartment of the spectrometer were made in order to accommodate the cryostat head and allow efficient purging of the instrument by a stream of dry air to remove water and $\mathrm{CO}_{2}$ vapors. After depositing the compound, annealing experiments were performed up to a temperature of $35 \mathrm{~K}$.

\subsection{Computational methodology}

The quantum chemical calculations were performed with Gaussian 03 (Revision C.02) [20], at the DFT and MP2 levels of theory with different basis sets $[6-31++G(d, p), 6-311++G(d, p)$, 6$311++G(3 d f, 3 p d)]$. The DFT calculations were carried out with the three-parameter density functional abbreviated as B3LYP, which includes Becke's gradient exchange correction [21] and the Lee, Yang and Parr correlation functional [22].

Table 1

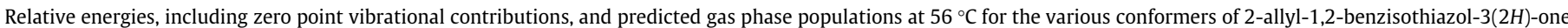
1,1-dioxide ${ }^{\mathrm{a}}$

\begin{tabular}{|c|c|c|c|c|c|c|}
\hline \multirow[t]{2}{*}{ Conformer } & \multicolumn{2}{|c|}{ DFT(B3LYP)/6-311++G(d,p) } & \multicolumn{2}{|c|}{ DFT(B3LYP)/6-311++G(3df,3pd) } & \multicolumn{2}{|l|}{$\mathrm{MP} 2 / 6-31++\mathrm{G}(\mathrm{d}, \mathrm{p})$} \\
\hline & $\triangle \mathrm{E} Z \mathrm{PE}$ & Population (\%) ${ }^{\mathrm{b}}$ & $\triangle \mathrm{E} Z \mathrm{PE}$ & Population (\%) ${ }^{\mathrm{b}}$ & $\triangle \mathrm{E} Z \mathrm{PE}$ & Population (\%) \\
\hline$S k$ & $0.0(-2796275.625)^{c}$ & 46.6 & $0.0(-2796544.810)^{c}$ & 46.2 & $0.0(-2789400.806)^{c}$ & 39.3 \\
\hline$S k^{\prime}$ & 0.55 & 38.1 & 0.68 & 36.0 & 0.64 & 31.1 \\
\hline C & 3.06 & 15.2 & 2.61 & 17.8 & 0.78 & 29.6 \\
\hline
\end{tabular}

\footnotetext{
a Energies in $\mathrm{kJ} \mathrm{mol}^{-1}$; conformers are depicted in Fig. 1.

b According to Boltzmann distribution at $56{ }^{\circ} \mathrm{C}$ (temperature of deposition).

c Total energies with zero point vibrational energy contribution.
} 
Structures were optimized using the Geometry Direct Inversion of the Invariant Subspace (GDIIS) method [23,24]. Vibrational frequencies were calculated at the same levels of theory and the nature of the stationary points on the potential energy surface resulting from optimization was determined by inspection of the corresponding calculated Hessian matrix. The optimized structures of all conformers were confirmed to correspond to true minimum energy conformations on the PES. Normal coordinate analyses were undertaken in the internal coordinates space as described by Schachtschneider [25], using the program BALGA [26], and the optimized geometries and harmonic force constants resulting from the DFT(B3LYP)/6-311++G(3df,3pd) calculations. Potential energy profiles for internal rotation were calculated performing a relaxed scan on the PES along the relevant reaction coordinates, and the transition state structures for conformational interconversion obtained using the Synchronous Transit-Guided Quasi-Newton (STQN) method [27,28].

\section{Results and discussion}

\subsection{Geometries and energies}

The molecule of ABIOD (Fig. 1) can be considered as being composed of two fragments: the heterocyclic ring, which bears a carbonyl substituent at the position $3\left(\mathrm{C}_{9}\right.$, in consonance with the adopted atom numbering scheme; see Fig. 1), and the conformationally flexible allyl substituent bound to the nitrogen atom of the heterocycle. The allyl substituent has a priori two conformationally relevant internal rotation axes, defined by the $\mathrm{C}_{9} \mathrm{~N}_{8} \mathrm{C}_{17} \mathrm{C}_{20}$ and $\mathrm{N}_{8} \mathrm{C}_{17} \mathrm{C}_{20}=\mathrm{C}_{22}$ dihedral angles. However, because of sterical hindrance, in the minimum energy conformations the $\mathrm{C}_{9} \mathrm{~N}_{8} \mathrm{C}_{17} \mathrm{C}_{20}$ axis was shown to assume always a conformation nearly perpendicular to the ring plane. Therefore, in practical terms, only the $\mathrm{N}_{8} \mathrm{C}_{17} \mathrm{C}_{20}=\mathrm{C}_{22}$ dihedral angle defines the conformational states of the molecule.

A conformational search on the ABIOD potential energy surface yielded three different conformers, differing in the $\mathrm{N}_{8} \mathrm{C}_{17} \mathrm{C}_{20}=\mathrm{C}_{22}$ dihedral angle (see Fig. 1 ). The structural parameters of these conformers, obtained at the different levels of theory used as study, are provided as Supplementary Material (Table S1).

Following the general trend exhibited by heteroallyl compounds, as discussed in detail by Kobychev et al. [29], the two skew conformers ( $S k$ and $S k^{\prime}$ ) were predicted to be more stable than the

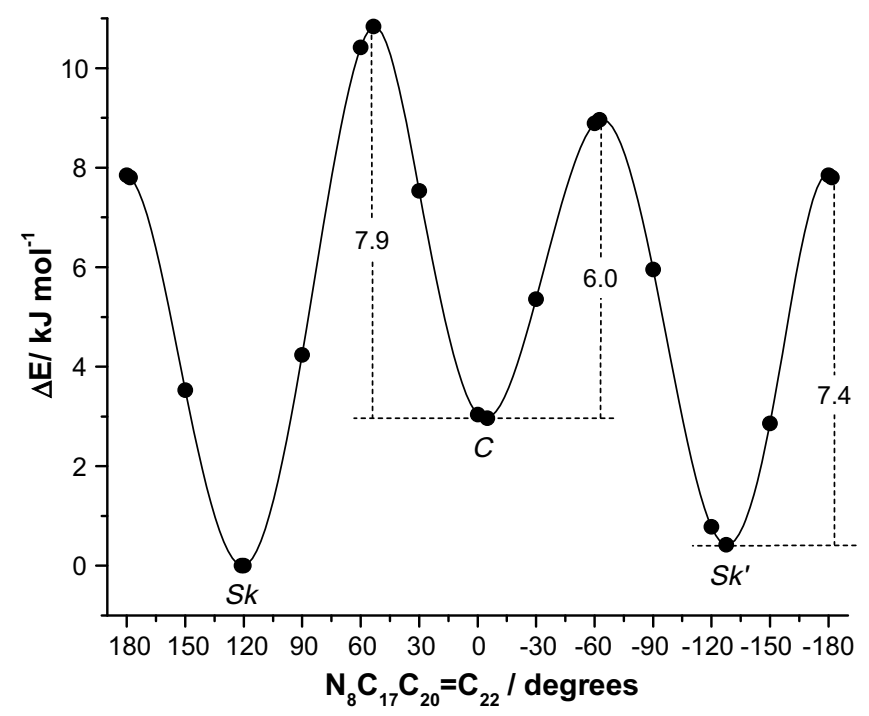

Fig. 2. DFT(B3LYP)/6-311++G(d,p) calculated potential energy profile for internal rotation around the $C_{17}-C_{20}$ bond. cis (C) form. The most stable conformer was found to be $S k$, with the zero point corrected relative energies of the $S k^{\prime}$ and $C$ conformers being ca. $0.6 \mathrm{~kJ} \mathrm{~mol}^{-1}$ and in the range $0.8-3.1 \mathrm{~kJ} \mathrm{~mol}^{-1}$ (depending on the level of theory used), respectively (Table 1 ). This last value can be compared with the available $\Delta \mathrm{E}_{\text {cis-skew }}$ values for 3-hydroxyprop-1-ene, 3-methoxyprop-1-ene, formoxime allyl ether, 3-dimethylaminoprop-1-ene and 3-(allyloxy)-1,2-benzisothiazole 1,1-dioxide, that are molecules exhibiting the $\mathrm{X}$ $\mathrm{CH}_{2} \mathrm{CH}=\mathrm{CH}_{2}$ moiety $(\mathrm{X}=\mathrm{O}$ or $\mathrm{N}$ ), analogous to the conformationally relevant fragment in $\mathrm{ABIOD}$, which range from 0.4 to $4.0 \mathrm{~kJ} \mathrm{~mol}^{-1}[29,30]$.

The potential energy profile corresponding to the rotation around the $\mathrm{N}_{8} \mathrm{C}_{17} \mathrm{C}_{20}=\mathrm{C}_{22}$ dihedral angle, which shows the pathways for interconversion between the three conformers of ABIOD is depicted in Fig. 2. As shown in this figure, the lowest energy barrier is associated with the $C \rightarrow S k^{\prime}$ isomerization $\left(6.0 \mathrm{~kJ} \mathrm{~mol}^{-1}\right)$, whereas the $C \rightarrow S k$ and $S k^{\prime} \rightarrow S k$ isomerization barriers were calculated to be 7.9 and $7.4 \mathrm{~kJ} \mathrm{~mol}^{-1}$, respectively.

\subsection{Infrared spectrum of the as-deposited matrix isolated $A B I O D$}

As shown in the previous section, the conformers of ABIOD have relatively close energies. The estimated populations for these conformers, based on the calculated relative energies obtained at the different levels of theory used in this study, are given in Table 1 for the temperature of sublimation of the compound in the matrix-isolation experiments $\left(56^{\circ} \mathrm{C}\right)$. In consonance with these data, all three conformers should have significant populations in the gas phase prior to deposition. On the other hand, the calculated energy barriers for conformational conversion from higher to lower energy forms are all in the range of values that may allow for some conformational cooling to take place during matrix deposition or

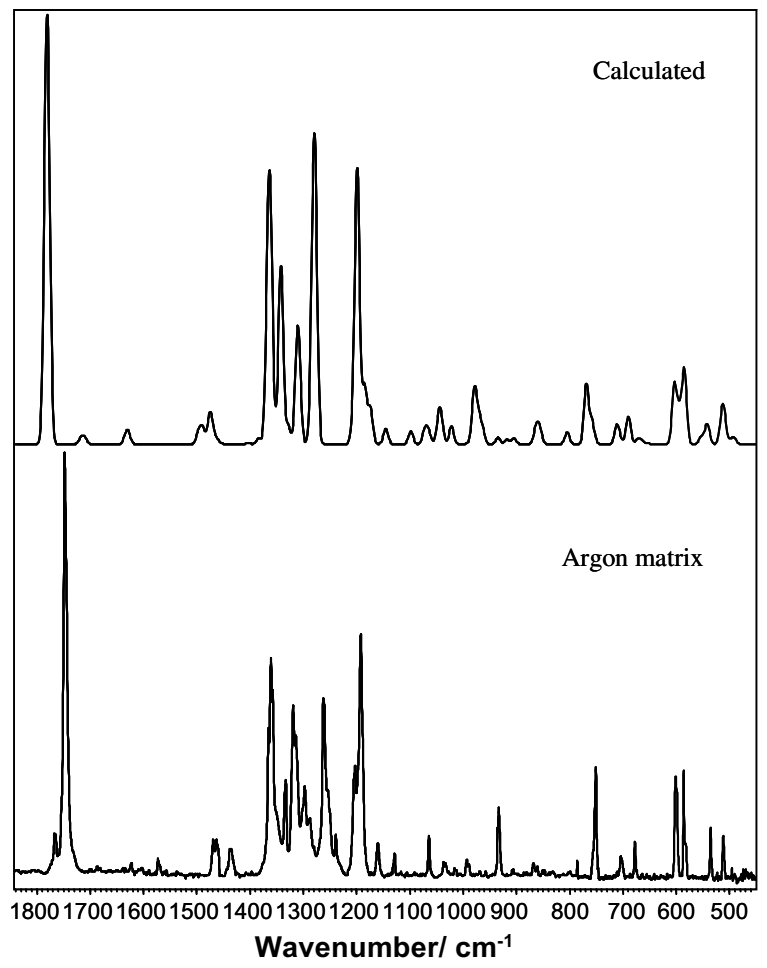

Fig. 3. Infrared spectra (1850-450 $\mathrm{cm}^{-1}$ region) of ABIOD trapped in an argon matrix obtained immediately after deposition at $10 \mathrm{~K}$ (bottom), and simulated spectra obtained by summing the calculated spectra for $S k, S k^{\prime}$ and $C$ conformers at the B3LYP/6-311++G(3df,3pd) level of theory, scaled by their estimated Boltzmann populations. 

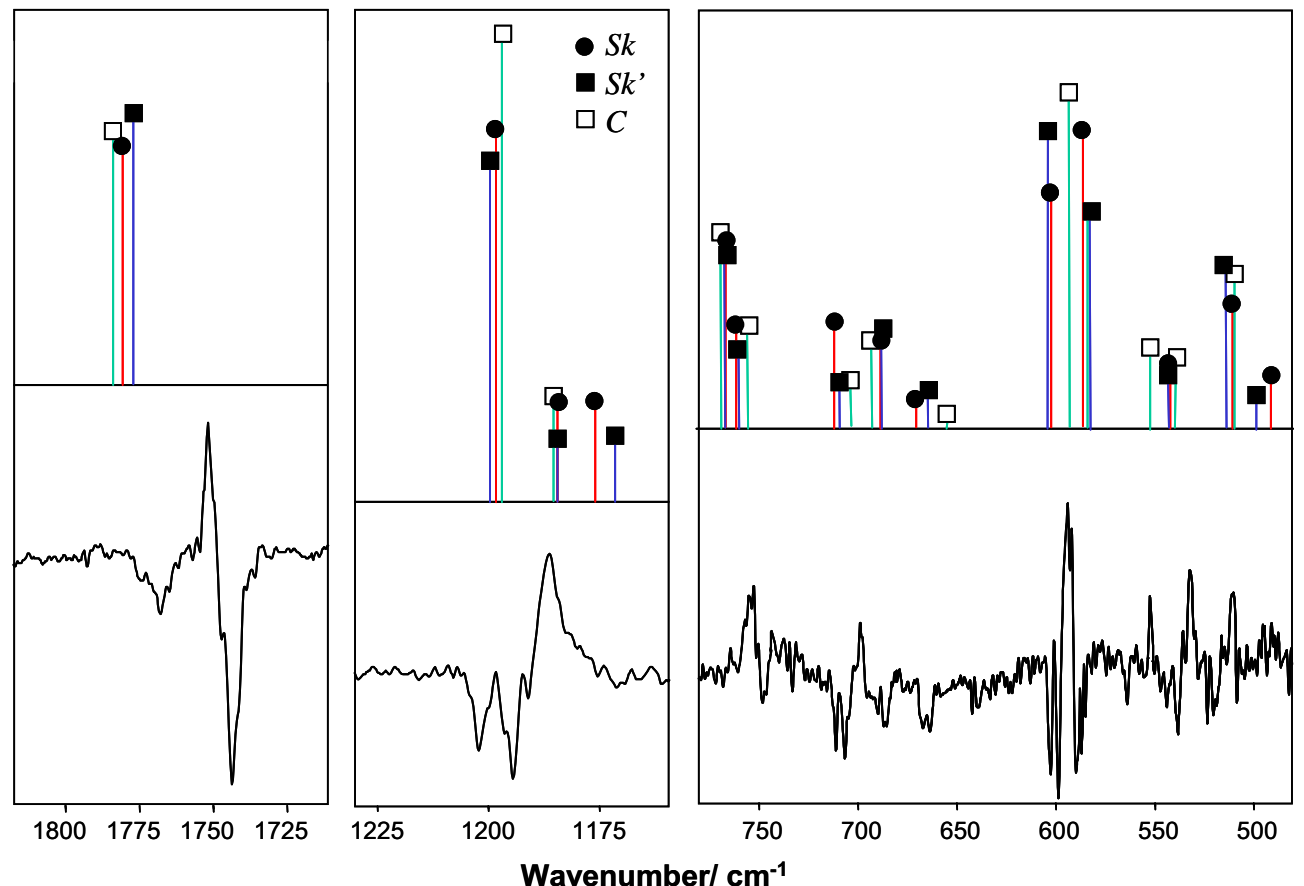

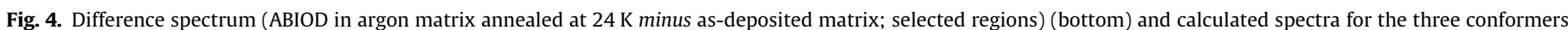

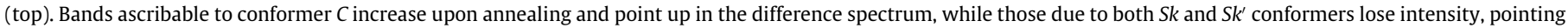

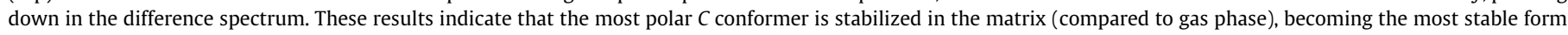
under these experimental conditions.

upon annealing of the matrix to higher temperatures. Conformational cooling during the deposition of the matrix is quite often observed in matrix-isolation experiments for molecules having conformers separated by low energy barriers (lower than a few $\mathrm{kJ} \mathrm{mol}^{-1}$ ) and have been discussed in detail in some of our previous studies [31-35].

The spectrum of the as-deposited matrix of ABIOD in argon is shown in Fig. 3. As discussed below, the detailed analysis of the observed spectrum doubtlessly shows that the three ABIOD conformers are present in this matrix. The simulated IR spectrum shown in Fig. 3 (upper panel) was built by adding the calculated individual spectra of the three conformers [calculated at the DFT(B3LYP)/6$311++G(3 d f, 3 p d)$ level of theory] scaled by the corresponding estimated populations in the gas phase at the sublimation temperature. As shown in the figure, the simulated spectrum reproduces well the observed spectrum of the as-deposited matrix.

In spite of the general good agreement between the experimental spectrum and the simulated one, identification of spectral features originated in a single conformer is not easy, since the predicted spectra of the three conformers of ABIOD do not differ extensively. Indeed, from the 66 vibrational modes of ABIOD, 35 are due to vibrations of the rings, which are not significantly affected by the changes of conformation in the allyl fragment. In addition, only some of the modes localized in this latter group or in the $\mathrm{SO}_{2}$ and $\mathrm{C}=\mathrm{O}$ substituents of the benzisothiazol ring (which are located in the proximity of the allyl group and can be expected to feel the effects of the changes in the conformation of this group) were predicted to be sensitive enough to conformational changes. Among those, the relatively intense carbonyl and $\mathrm{SO}_{2}$ symmetric stretching bands (around 1750 and $1200 \mathrm{~cm}^{-1}$, respectively) as well as a group of bands in the low frequency spectral range (500-800 $\mathrm{cm}^{-1}$ ) could be used successfully to check for the presence of the three conformers in the matrix during the annealing experiments (Fig. 4).

Annealing of the matrix at $24 \mathrm{~K}$ resulted in changes in the relative intensities of bands. Fig. 4 shows some relevant spectral re- gions where these changes are more easily observed. Table 2 presents the full spectrum assignment, which relies in both the comparison of the observed spectrum with the calculated spectra of the conformers and the results of the annealing experiments (complete calculated spectra and results of normal coordinate analysis are provided in Tables S2-S5 as Suplementary Information). It is clear that annealing of the matrix promotes conversion of both $S k$ and $S k^{\prime}$ conformers into the $C$ form, resulting in upward pointing bands in the difference spectrum shown in Fig. 4 belonging to this conformer. This result can only be explained considering that the $C$ form becomes the most stable ABIOD conformer in the matrix. This stabilization of the $C$ form compared with $S k$ and $S k^{\prime}$ conformers in the matrix, in going from the gas phase to the matrix conditions, results with all probability from its slightly higher polarity, though a more favourable packing may also contribute to this phenomenon. It is interesting to note that a somewhat similar effect has been previously observed for 3-(allyloxy)-1,2-benzisothiazole 1,1-dioxide [30].

It is also worth noticing that the temperature at which the conformational conversion starts being efficient $(24 \mathrm{~K})$ is, according to the Barnes' relationship [36], consistent with conversion energy barriers of $c a .6 \mathrm{~kJ} \mathrm{~mol}^{-1}$. This value is similar to predicted energy barriers for the gas phase, indicating that, in spite of the change in the potential energy surface due to interaction with the matrix (which includes the change of order of the relative stabilities of the conformers), the barriers for conformational isomerisation did not change appreciably upon going from the gas phase to the matrix environment.

An independent check for the relative stability of the conformers in the gaseous phase was also made in the present study by examining in deeper detail the carbonyl stretching region. In this spectral region, two main features are observed: the intense band at $c a .1750 \mathrm{~cm}^{-1}$, which as shown in Fig. 4 contains contributions from the three conformers, and a small band at $1765 \mathrm{~cm}^{-1}$. This latter band belongs, with all probability, to the Skew conformers, since it decreases upon annealing of the 
matrix, and can be ascribed to the $v \mathrm{~N}-\mathrm{S}+\gamma \mathrm{C}-\mathrm{H}_{11}$ combination tone, whose fundamentals are observed at 1016 and $752 \mathrm{~cm}^{-1}$, respectively (Table 2). Fig. 5 shows the result of deconvolution of the $1750 \mathrm{~cm}^{-1}$ band as observed in the as-deposited matrix spectrum. As clearly shown in this figure, the band comprehends three components, which are ascribable to the three ABIOD conformers. The percent contribution of the three components to the observed feature, weighted by the relative calculated carbonyl stretching intensities for the conformers are 45.3\%, 31.1\% and $23.6 \%$, for $S k, S k^{\prime}$ and $C$ conformers. These percentages fit very well the relative abundances of the conformers predicted by the calculations in the gas phase at the temperature $\left(56^{\circ} \mathrm{C}\right)$ of the vapour immediately before deposition of the matrix (average values: $44 \%, 35 \%$ and $21 \%$, respectively; see Table 1 ), thus confirming the theoretical predictions regarding the relative stability of the conformers in the gas phase and, in particular, proving that the $S k$ conformer is the most stable form in this phase. These results also reinforce the idea that, under the experimental conditions used, no significant conformational cooling took place during deposition of the matrix.

Table 2

Assignment of the observed spectrum of 2-allyl-1,2-benzisothiazol-3(2H)-one 1,1-dioxide in argon matrix ${ }^{\mathrm{a}}$

\begin{tabular}{|c|c|c|c|c|}
\hline \multirow[t]{2}{*}{ Approximate description ${ }^{\mathrm{b}}$} & \multicolumn{3}{|c|}{ Calculated B3LYP/6-311++(3df,3pd) } & \multirow[t]{2}{*}{ Observed argon matrix $(10 \mathrm{~K})\left(\mathrm{v} / \mathrm{cm}^{-1}\right.$} \\
\hline & $S k$ & $S k^{\prime}$ & $C$ & \\
\hline $\mathrm{v}\left(=\mathrm{CH}_{2}\right) \mathrm{as}$ & 3221.5 & 3222.3 & 3234.2 & \multirow{5}{*}{3209} \\
\hline$v(\mathrm{C}-\mathrm{H}$ ring 1$)$ & 3210.0 & 3210.0 & 3210.0 & \\
\hline $\mathrm{v}(\mathrm{C}-\mathrm{H}$ ring 2$)$ & 3206.8 & 3206.9 & 3206.9 & \\
\hline $\mathrm{v}(\mathrm{C}-\mathrm{H}$ ring 3$)$ & 3195.6 & 3195.3 & 3195.6 & \\
\hline$v(\mathrm{C}-\mathrm{H}$ ring 4$)$ & 3182.8 & 3182.4 & 3182.7 & \\
\hline $\mathrm{vCH}$ & 3160.0 & 3153.9 & 3139.8 & \multirow{2}{*}{3031} \\
\hline $\mathrm{v}\left(=\mathrm{CH}_{2}\right) \mathrm{s}$ & 3135.8 & 3135.5 & 3153.4 & \\
\hline$v\left(\mathrm{CH}_{2}\right)$ as & 3108.9 & 3097.8 & 3074.2 & \multirow{2}{*}{2934} \\
\hline$v\left(\mathrm{CH}_{2}\right) \mathrm{s}$ & 3048.3 & 3051.2 & 3036.2 & \\
\hline$v C=0$ & 1780.6 & 1777.1 & 1783.6 & $1750(C) ; 1748(S k) ; 1744\left(S k^{\prime}\right)$ \\
\hline$v C=C$ & 1709.5 & 1710.1 & 1716.9 & 1686 \\
\hline$v(C-C$ ring 4$)$ & 1632.7 & 1632.8 & 1633.0 & 1572 \\
\hline $\mathrm{v}(\mathrm{C}-\mathrm{C}$ ring 2$)$ & 1627.8 & 1628.0 & 1627.9 & 1568 \\
\hline$v(C-C$ ring 6$)$ & 1496.2 & 1496.3 & 1496.8 & 1469 \\
\hline$v(C-C$ ring 5$)$ & 1488.8 & 1488.9 & 1488.8 & $1463 / 1461$ \\
\hline$\delta \mathrm{CH} 2$ & 1476.3 & 1473.8 & 1470.0 & 1437 \\
\hline$\delta\left(=\mathrm{CH}_{2}\right)$ & 1461.8 & 1461.7 & 1453.3 & $1434\left(S k, S k^{\prime}\right) ; 1431(C)$ \\
\hline $\mathrm{wCH}_{2}$ & 1383.1 & 1383.1 & 1402.8 & $1371\left(S k, S k^{\prime}\right) ;$ n.obs. $(C)$ \\
\hline $\mathrm{vSO}_{2}$ as & 1361.2 & 1366.5 & 1364.4 & $1366\left(S k^{\prime}, C\right) 1361(S k)$ \\
\hline$v(C-C$ ring 3$)$ & 1358.4 & 1359.3 & 1359.4 & 1357 \\
\hline $\mathrm{twCH}_{2}$ & 1341.4 & 1340.1 & 1344.1 & 1348 \\
\hline$\delta(=\mathrm{CH})$ & 1327.5 & 1326.0 & 1328.4 & 1332 \\
\hline$\delta(\mathrm{C}-\mathrm{H}$ ring 1$)$ & 1309.1 & 1306.5 & 1312.0 & $1321(C) ; 1317(S k) ; 1314\left(S k^{\prime}\right)$ \\
\hline$v C-N$ & 1279.0 & 1276.3 & 1282.7 & $1266(C) ; 1261 / 1253 / 1239\left(S k, S^{\prime}\right)$ \\
\hline$\delta(\mathrm{C}-\mathrm{H}$ ring 4$)$ & 1205.5 & 1204.2 & 1207.1 & $1208 / 1203$ \\
\hline $\mathrm{vSO}_{2} \mathrm{~S}$ & 1198.0 & 1198.8 & 1197.6 & $1198\left(S k^{\prime}\right) ; 1192(S k) ; 1186(C)$ \\
\hline$\delta(\mathrm{C}-\mathrm{H}$ ring 3$)$ & 1184.5 & 1184.5 & 1185.3 & 1175 \\
\hline $\mathrm{w}\left(=\mathrm{CH}_{2}\right)$ & 1174.9 & 1171.6 & 1097.7 & $1161\left(S k, S k^{\prime}\right) ; 1155(C)$ \\
\hline$\delta(\mathrm{C}-\mathrm{H}$ ring 2$)$ & 1143.9 & 1144.2 & 1146.1 & 1129 \\
\hline$\delta($ ring 1$)$ & 1071.4 & 1071.7 & 1074.3 & 1092 \\
\hline$v \mathrm{~N}-\mathrm{S}$ & & & 1064.5 & $1029(C)$ \\
\hline$\gamma \mathrm{CH} 2$ & & 1045.5 & & 1037 \\
\hline$v(C-C$ ring 1$)$ & 1043.6 & 1040.1 & 1041.1 & \\
\hline$\gamma \mathrm{C}-\mathrm{H}$ & 1039.5 & 1023.4 & 1022.7 & 1033 \\
\hline$\gamma \mathrm{C}-\mathrm{H}_{12}$ & 1022.6 & 1023.1 & 1023.7 & \\
\hline$\gamma \mathrm{N}-\mathrm{S}$ & 1021.2 & & & 1016 \\
\hline$\gamma \mathrm{C}-\mathrm{H}_{10}$ & 988.7 & 989.7 & 989.3 & 1006 \\
\hline $\mathrm{vN}-\mathrm{C}$ & & 980.5 & 978.6 & 993 \\
\hline$\gamma\left(=\mathrm{CH}_{2}\right)$ & 977.5 & 970.9 & 962.9 & $988\left(S k^{\prime}\right) ; 969(S k, C)$ \\
\hline $\mathrm{vN}-\mathrm{C}$ & 966.1 & & & 958 \\
\hline$v C-C$ & 934.1 & 917.2 & 904.2 & 935/933 (Sk, $\left.S k^{\prime}\right) ; 928 / 919(C)$ \\
\hline$\gamma \mathrm{C}-\mathrm{H}_{13}$ & 907.1 & 907.8 & 907.3 & 906 \\
\hline$\delta \mathrm{C}=\mathrm{O}$ & & 862.0 & & $868 / 861\left(S k, S k^{\prime}\right) ; 851 / 848(C)$ \\
\hline$\gamma \mathrm{CH}_{2}$ & 856.0 & & 864.2 & \\
\hline$\gamma \mathrm{C}=\mathrm{O}$ & 803.9 & 804.4 & 805.2 & 785 \\
\hline$\gamma \mathrm{C}-\mathrm{H}_{11}$ & 767.9 & 768.5 & 769.2 & $756 / 749(C) ; 752 / 746$ (?) $\left(S k, S k^{\prime}\right)$ \\
\hline$\delta($ ring 2) & 759.1 & 760.0 & 755.6 & \\
\hline$\delta($ ring 3$)$ & 711.8 & 709.7 & 705.5 & $710(S k) ; 704\left(S k^{\prime}\right) ; 698(C)$ \\
\hline$\tau(\mathrm{C}-\mathrm{C}$ ring 1$)$ & 688.5 & 688.9 & 691.6 & $678(\mathrm{C}) ; 673\left(S k, S k^{\prime}\right)$ \\
\hline$\tau \mathrm{C}=\mathrm{C}$ & 672.4 & 665.3 & & 656 \\
\hline$\delta \mathrm{C}-\mathrm{C}=\mathrm{C}$ & & & 653.9 & n. obs. \\
\hline$\gamma \mathrm{SO}_{2}$ & 602.7 & 604.0 & 594.4 & $602\left(S k^{\prime}\right) ; 599(S k) ; 593 / 591(C)$ \\
\hline$\delta \mathrm{SO}_{2}$ & 586.0 & 583.7 & 583.2 & $587(S k) ; 582\left(S k^{\prime}, C\right)$ \\
\hline$\tau \mathrm{C}=\mathrm{C}$ & & & 552.9 & 542 \\
\hline $\mathrm{wSO}_{2}$ & 542.3 & 543.2 & 539.3 & $536\left(S k, S k^{\prime}\right) ; 530(C)$ \\
\hline$\delta(\mathrm{T}$-ring 2$)$ & 511.7 & 514.8 & & 512 \\
\hline $\mathrm{vN}-\mathrm{S}$ & & 499.7 & & 496 \\
\hline$\delta \mathrm{C}=\mathrm{O}$ & 491.7 & & 509.6 & $509(C) ; 496(S k)$ \\
\hline
\end{tabular}

${ }^{a}$ The full calculated spectra for the ABIOD conformers, with full potential energy distribution results, are provided in Tables S3-S5 as Supporting Information.

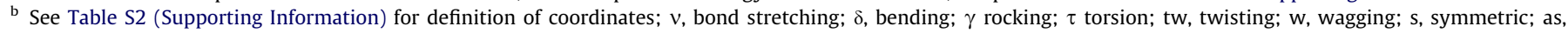
asymmetric; n. obs., not observed. 


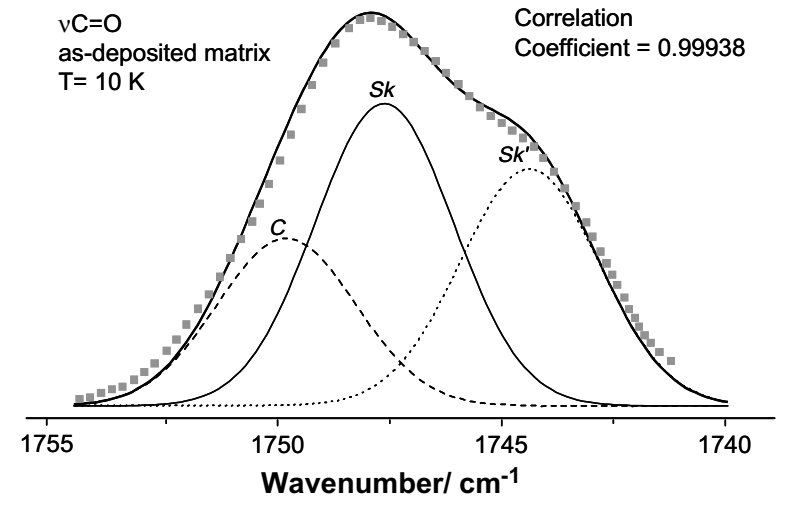

Fig. 5. Deconvolution of the $v C=O$ band of the infrared spectrum of $A B I O D$ in the as-deposited argon matrix. The relative conformational populations predicted based on the analysis of the data shown in this figure are in agreement with those obtained from the theoretical energy calculations (see text). The points correspond to the experimental data; the tick solid line to the fitted curve, whose components have maxima at 1744,1748 and $1750 \mathrm{~cm}^{-1}$.

\section{Conclusions}

In this work, ABIOD has been for the first time isolated in an argon matrix. In consonance with high level DFT(B3LYP)/6$311++G(3 d f, 3 p d)$ calculations, the matrix-isolation spectroscopic data reveal the presence in the as-deposited matrix of the three different ABIOD conformers that were theoretically predicted to have similar energies in the gaseous phase: $S k, S k^{\prime}$ and $C$. According to the calculations, the $S k$ form is the most stable conformer in the gaseous phase, whereas the $S k^{\prime}$ and $C$ conformers have calculated relative energies of $c a$. 0.6 and $0.8-3.0 \mathrm{~kJ} \mathrm{~mol}^{-1}$, respectively (depending on the level of theory). These results are in consonance with the fact that the experimental infrared spectrum of the asdeposited matrix fits well the simulated spectrum built from the calculated spectra of the individual conformers scaled by their predicted populations at the temperature of the vapour of the compound prior to matrix deposition.

On the other hand, annealing of the matrix at $24 \mathrm{~K}$ was found to lead to conversion of both $S k$ and $S k^{\prime}$ conformers to the more polar $C$ form, revealing that this conformer becomes the most stable one in the matrix.

\section{Acknowledgements}

Calculations were partially done at the Academic Computer Center "Cyfronet", Krakow, Poland (Grant KBN/SGI_ORIGIN_2000/ $\mathrm{UJ} / 044 / 1999$ ), which is acknowledged for computing time. The research was also supported by the Portuguese Fundação para a Ciência e a Tecnologia and FEDER (Project PTDC/QUI/67674/2006 and Grant SFRH/BPD/17081/2004) and ANPCyT (Project PICT 2006 - 0068). AGZ is member of the Research Career at the National Research Council (Conicet), Argentina.

\section{Appendix A. Supplementary data}

Supplementary data associated with this article can be found, in the online version, at doi:10.1016/j.molstruc.2008.09.013.

\section{References}

[1] M. Otten, W. von Deyn, S. Engel, R. Hill, U. Kardorff, M. Vossen, P. Plath, Isoxazole-4-yl-benzoyl derivatives and their use as herbicides, Patent No. WO/ 1997/19076, Internationale Anmeldung Veroffentlicht nach dem Vertrag uber die Internationale Zusammenargeit auf dem Gebiet des Patentwesens, Weltorganisationfur Geistiges Eigentum, 1997.

[2] P.J. Wepplo, R.A. Rampulla, G.D. Heffernan, M.V. Cosette, R.E. Diehl, J.J. Fiordeliso, G.J. Haley, M.A. Guaciaro, Herbicidal 3-heterocyclic substituted benzisothiazole and benzisoxazole compounds, Patent No. WO/2001/079203, Internationale Anmeldung Veroffentlicht nach dem Vertrag uber die Internationale Zusammenargeit auf dem Gebiet des Patentwesens, Weltorganisationfur Geistiges Eigentum, 2001.

[3] M.B. Gravestock, Bicyclic heterocyclic substituted phenyl oxazolidinone antibacterials, and related compositions and methods, Patent No. WO/1999/ 10342, Internationale Anmeldung Veroffentlicht nach dem Vertrag uber die Internationale Zusammenargeit auf dem Gebiet des Patentwesens, Weltorganisationfur Geistiges Eigentum, 1999.

[4] P.I. Eacho, P.S. Foxworthy-Mason, H.-S. Lin, J.E. Lopez, M. Mosior, M.E. Richett, Benzisothiazol-3-one-carboxylic acid amides as phospholipase inhibitors, Patent No. WO/2004/094394, Internationale Anmeldung Veroffentlicht nach dem Vertrag uber die Internationale Zusammenargeit auf dem Gebiet des Patentwesens, Weltorganisationfur Geistiges Eigentum, 2004.

[5] C.L. Winder, I.S.I. Al-Adham, S.M.A. Abdel Malek, T.E.J. Buultjens, A.J. Horrocks, P.J.J. Collier, Appl. Microbiol. 89 (2000) 289.

[6] D.J. Hlasta, M.R. Bell, J.J. Court, K.C. Cundy, R.C. Desai, E.W. Ferguson, R.J. Gordon, V. Kumar, A.L. Maycock, Ch. Subramanyam, Bioorg. Med. Chem. Lett. 5 (1995) 331.

[7] Ch. Subramanyam, M.R. Bell, E. Ferguson, R.G. Gordon, R.P. Dunlap, C. Franke, A. Mura, J. Bioorg. Med. Chem. Lett. 5 (1995) 319.

[8] K.-L. Yu, R. Civiello, D.G.M. Roberts, S.M. Seiler, N.A. Meanwell, Bioorg. Med. Chem. Lett. 9 (1999) 663.

[9] L.H. Wang, X.Y. Yang, X.H. Zhang, K. Mihalic, Y.X. Fan, W.H. Xiao, O.M.Z. Howard, E. Appella, A.T. Maynard, W.L. Farrar, Nat. Med. 10 (2004) 40.

[10] L. Sharmeen, T. McQuade, A. Heldsinger, R. Gogliotti, J. Domagala, S. Gracheck, Antiviral Res. 49 (2001) 101.

[11] A.F. Brigas, R.A.W. Johnstone, Tetrahedron Lett. 31 (1990) 5789.

[12] N.C.P. Araújo, A.F. Brigas, M.L.S. Cristiano, L.M.T. Frija, E.M.O. Guimarães, R.M.S. Loureiro, J. Mol. Catal. A 215 (2004) 113.

[13] L.M.T. Frija, M.L.S. Cristiano, E.M.O. Guimarães, N.C. Martins, R.M.S. Loureiro, J Bickley, J. Mol. Catal. A 242 (2005) 241.

[14] A.F. Brigas, R.A.W. Johnstone, J. Chem. Soc., Perkin Trans. 1 (2000) 1735.

[15] J.A.C. Alves, J.V. Barkley, A.F. Brigas, R.A.W. Johnstone, J. Chem. Soc., Perkin Trans. 2 (1997) 669.

[16] J.V. Barkley, M.L.S. Cristiano, R.A.W. Johnstone, R.M.S. Loureiro, Acta Crystallogr. Sect. C Cryst. Struct. Commun. 53 (1997) 383.

[17] M.L.S. Cristiano, A.F. Brigas, R.A.W. Johnstone, R.M.S. Loureiro, P.C.A. Pena, J. Chem. Res. (S) (1999) 704

[18] N.C.P. Araújo, P.M.M. Barroca, J.F. Bickley, A.F. Brigas, M.L.S. Cristiano, R.A.W. Johnstone, R.M.S. Loureiro, P.C.A. Pena, J. Chem. Soc., Perkin Trans. 1 (2002) 1213.

[19] R. Almeida, A. Gómez-Zavaglia, A. Kaczor, M.L.S. Cristiano, M.E.S. Eusébio, T.M.R. Maria, R. Fausto, Tetrahedron 64 (2008) 3296.

[20] M.J. Frisch, G.W. Trucks, H.B. Schlegel, G.E. Scuseria, M.A. Robb, J.R. Cheeseman, J.A. Montgomery Jr., T. Vreven, K.N. Kudin, J.C. Burant, J.M. Millam, S.S. Iyengar, J. Tomasi, V. Barone, B. Mennucci, M. Cossi, G. Scalmani, N. Rega, G.A. Petersson, H. Nakatsuji, M. Hada, M. Ehara, K. Toyota, R. Fukuda, J. Hasegawa, M. Ishida, T. Nakajima, Y. Honda, O. Kitao, H. Nakai, M. Klene, X. Li, J.E. Knox, H.P. Hratchian, J.B. Cross, V. Bakken, C. Adamo, J. Jaramillo, R. Gomperts, R.E. Stratmann, O. Yazyev, A.J. Austin, R. Cammi, C. Pomelli, J.W. Ochterski, P.Y. Ayala, K. Morokuma, G.A. Voth, P. Salvador, J.J. Dannenberg, V.G. Zakrzewski, S. Dapprich, A.D. Daniels, M.C. Strain, O. Farkas, D.K. Malick, A.D. Rabuck, K. Raghavachari, J.B. Foresman, J.V. Ortiz, Q. Cui, A.G. Baboul, S. Clifford, J. Cioslowski, B.B. Stefanov, G. Liu, A. Liashenko, P. Piskorz, I. Komaromi, R.L. Martin, D.J. Fox, T. Keith, M.A. Al-Laham, C.Y. Peng, A. Nanayakkara, M. Challacombe, P.M.W. Gill, B. Johnson, W. Chen, M.W. Wong, C. Gonzalez, J.A. Pople, Gaussian 03, Revision C.02, Gaussian, Inc., Wallingford, CT, 2004.

[21] A.D. Becke, Phys. Rev. A 38 (1988) 3098.

[22] C.T. Lee, W.T. Yang, R.G. Parr, Phys. Rev. B 37 (1988) 785

[23] P. Csaszar, P. Pulay, J. Mol. Struct. (Theochem) 114 (1984) 31.

[24] Ö. Farkas, H.B.J. Schlegel, Chem. Phys. 111 (1999) 10806.

[25] J.H. Schachtschneider, Technical Report, Shell Development Co., Emeryville, CA, 1969.

[26] This program has been kindly made available to us by Dr. L. Lapinski, Institute of Physics, Polish Academy of Sciences, Al. Lotnikow 32/46, 02-668 Warsaw, Poland.

[27] C. Peng, H.B. Schlegel, Isr. J. Chem. 33 (1993) 449.

[28] C. Peng, P.Y. Ayala, H.B. Schlegel, M.J. Frisch, J. Comp. Chem. 17 (1996) 49.

[29] V.B. Kobychev, E.Yu. Larionova, N.S. Klyba, J. Struct. Chem. 44 (2003) 748.

[30] A. Gómez-Zavaglia, A. Kaczor, R. Almeida, M.L.S. Cristiano, R. Fausto, J. Phys Chem. A 112 (2008) 1762.

[31] I.D. Reva, S.G. Stepanian, L. Adamowicz, R. Fausto, Chem. Phys. Lett. 374 (2003) 631.

[32] A. Gómez-Zavaglia, R. Fausto, Phys. Chem. Chem. Phys. 5 (2003) 52.

[33] A. Kaczor, I.D. Reva, L.M. Proniewicz, R. Fausto, J. Phys. Chem. A 110 (2006) 2360.

[34] I.D. Reva, A.J. Lopes Jesus, M.T. Rosado, R. Fausto, M.E. Eusébio, J.S. Redinha, Phys. Chem. Chem. Phys. 8 (2006) 5339.

[35] A. Borba, A. Gómez-Zavaglia, R. Fausto, J. Mol. Struct. 794 (2006) 196.

[36] A.J. Barnes, J. Mol. Struct. 113 (1984) 161. 